\title{
Pharmacokinetics of orally administered uracil in healthy volunteers and in DPD-deficient patients, a possible tool for screening of DPD deficiency
}

\author{
Maurice C. van Staveren • Barbara Theeuwes-Oonk • \\ Henk Jan Guchelaar • André B. P. van Kuilenburg • \\ Jan Gerard Maring
}

Received: 8 February 2011/Accepted: 16 April 2011/Published online: 18 May 2011

(c) The Author(s) 2011. This article is published with open access at Springerlink.com

\begin{abstract}
Purpose Dihydropyrimidine dehydrogenase (DPD) deficiency can lead to severe toxicity in patients treated with standard doses of 5-fluorouracil (5-FU). Oral uracil administration and subsequent measurement of uracil and dihydrouracil (DHU) plasma concentrations might detect patients with DPD deficiency. This study compares the pharmacokinetics of uracil and DHU after oral uracil administration in subjects with normal and deficient DPD status.

Methods Five hundred milligrams of uracil per metre square was administered orally to 11 subjects with normal DPD status and to 10 subjects with reduced DPD activity. Repeated administration $(n=3)$ of this dose was performed in 4 subjects, and $1,000 \mathrm{mg}$ uracil $/ \mathrm{m}^{2}$ was administered to 4 subjects to assess intra-individual variation and linearity of pharmacokinetics.
\end{abstract}

A part of the data were presented at ASCO 2004 by J. G. Maring.

M. C. van Staveren $(\square)$

Department of Pharmacy, Scheper Hospital Emmen and Röpcke Zweers Hospital Hardenberg,

Boermarkeweg 60, 7824 AA Emmen, The Netherlands

e-mail: m.vanstaveren@sze.nl

H. J. Guchelaar

Department of Clinical Pharmacy and Toxicology,

Leiden University Medical Center, Leiden, The Netherlands

A. B. P. van Kuilenburg

Laboratory Genetic Metabolic Diseases, Academic Medical

Center Amsterdam, Amsterdam, The Netherlands

B. Theeuwes-Oonk · J. G. Maring

Department of Pharmacy, Diaconessen Hospital Meppel

and Bethesda Hospital Hoogeveen, Meppel, The Netherlands
Results In subjects with normal DPD status, $500 \mathrm{mg} / \mathrm{m}^{2}$ uracil resulted in uracil $C_{\max }$ levels of $14.4 \pm 4.7 \mathrm{mg} / \mathrm{L}$ at $T_{\max }=30.0 \pm 11.6 \mathrm{~min}$, and in DPD-deficient subjects, $20.0 \pm 4.5 \mathrm{mg} / \mathrm{L}$ at $31.5 \pm 1.1 \mathrm{~min}$. The uracil $\mathrm{AUC}_{0>180}$ was $31.2 \pm 5.1 \mathrm{mg} \mathrm{L} / \mathrm{h}$ in DPD-deficient subjects, which was significantly higher $(P<0.05)$ than in the subjects with normal DPD status $(13.8 \pm 3.9 \mathrm{mg} \mathrm{L} / \mathrm{h})$. Repeated uracil dosing showed reproducible uracil PK in subjects with normal DPD status, and dose elevation of uracil suggested linear pharmacokinetics.

Conclusion The pharmacokinetics of uracil differs significantly between subjects with a normal DPD activity and those with a deficient DPD status. The AUC and $C_{\max }$ of uracil can be useful as a diagnostic tool to differentiate patients with regard to DPD status.

Keywords Dihydropyrimide dehydrogenase - Uracil · Cancer · 5-fluorouracil · Pharmacokinetics

\section{Introduction}

5-Fluorouracil and its prodrug capecitabine are commonly used chemotherapeutic drugs in the treatment of colorectal, breast, and head and neck cancer. The intracellular metabolism of 5-FU is complex, requiring conversion into cytotoxic nucleotides. The main cytotoxic metabolite is 5-fluoro-2'-deoxyuridine $5^{\prime}$-monophosphate that inhibits thymidylate synthase [1]. However, only a small proportion of the administrated 5-FU dose is converted to cytotoxic metabolites. Within a few hours after parenteral administration, $70-90 \%$ of the 5-FU dose is metabolized into inactive metabolites. DPD is the initial and rate-determining enzyme in the catabolism of 5-FU [2-5]. Patients with a partial or complete DPD deficiency have a strongly 
reduced capacity to degrade $5 \mathrm{FU}[6,7]$ or its oral prodrug capecitabine $[8,9]$. As a consequence, treatment with 5-FU and/or capecitabine in patients with reduced DPD activity can cause severe or life-threatening toxicity such as neutropenia, diarrhea, and mucositis [10]. It was initially estimated that in 3-5\% of Caucasians, the activity of DPD is strongly reduced due to (epi)genetic variations in the gene encoding DPD. However, this percentage can be disputed because the incidence of DPD deficiency depends on the method that is used to detect it [11] and the cutoff level chosen or determined to define DPD deficiency [12]. A recent study found DPD deficiency in $40 \%$ of the patients included using the uracil/dihydrouracil ratio in plasma, an observation higher than the outcome expected with DPYD genetic polymorphism [13].

Several methods have been developed to detect patients with reduced DPD activity, such as genotyping [14], determination of DPD activity in peripheral blood mononuclear cells (PBMCs) [4, 10], phenotyping with a breath test using $\left[2-{ }^{13} \mathrm{C}\right]$ uracil [15-17], the administration of a 5-FU test dose [7, 18], and assessment of the endogenous uracil/DHU plasma ratio [19-27]. A major drawback of many of these methods is that they are costly and/or laborious or in the case of a 5-FU test dose, potentially toxic, thus precluding the routine implementation in clinical practice for prospective screening of DPD deficiency. To achieve the most accurate and simple method to predict DPD deficiency prior to 5-FU- or capecitabine-based treatment, a combined testing strategy has been proposed $[12,21]$. However, oral administration of an uracil test dose and subsequent measurement of uracil and its metabolite DHU in plasma might be a cheap, fast, and simple method for screening of DPD deficiency prior to 5-FU or capecitabine containing therapy, which can be used clinically. So far, only the pharmacokinetics of orally administered ${ }^{13} \mathrm{C}$-uracil has been reported using low doses of 50, 100, and $200 \mathrm{mg}$ uracil. The major drawback of using low doses of uracil concerns the lower chance of reaching adequate plasma concentrations. The use of higher uracil doses is expected to result in a more adequate discrimination between normal and deficient individuals due to a prolonged DPD enzyme saturation in DPD-deficient subjects compared with lower doses of uracil. Moreover, this situation may better reflect the DPD enzyme dynamics in the clinical situation when 5-FU doses of 1,000-2,000 mg are being used. From previous work with 5-FU, we estimated that a uracil plasma level of at least $10 \mathrm{mg} / \mathrm{L}$ would be needed for proper discrimination between DPD-deficient and normal DPD subjects with high sensitivity and specificity [6].

The main objective of this study was to compare the pharmacokinetics of orally administered uracil between healthy volunteers with normal DPD activity and patients with DPD deficiency due to heterozygosity for a $D P Y D$ gene mutation. Secondary objectives involved the investigation of linearity of uracil pharmacokinetics at increased uracil dose and the intra- and interday variation in uracil pharmacokinetics.

\section{Materials and methods}

Study subjects

Eleven subjects with a normal DPD status and ten DPDdeficient subjects, aged 18 years and older, participated in this study. The eleven subjects were all healthy volunteers, and the ten DPD-deficient subjects were colorectal and breast cancer patients who suffered CTC grade III or IV side effects following a 5-FU or capecitabine containing drug schedules and had DPD activity $<5 \mathrm{nmol} / \mathrm{mg}$ protein/h. DPD activity was measured in PBMCs, and the DPD status was considered normal or deficient when the DPD activity in PBMCs was $>5 \mathrm{nmol} / \mathrm{mg}$ protein $/ \mathrm{h}$ or $<5 \mathrm{nmol} / \mathrm{mg}$ protein $/ \mathrm{h}$, respectively [11]. In all patients, DPD deficiency was confirmed by sequence analysis of DPYD showing heterozygosity for a pathological mutation. Heterozygosity for the c. $1905+1 \mathrm{G}>\mathrm{A}$ $(\mathrm{IVS} 14+1 \mathrm{G}>\mathrm{A})$, c. $2846 \mathrm{~A}>\mathrm{T}$, c. $1129-5923 \mathrm{C}>\mathrm{G}$, and the novel c.2579delA mutation was detected in 5, 2, 2, and 2 patients, respectively. One of the patients was heterozygous for both the c.1905+1G>A mutation and the c. $1129-5923 \mathrm{C}>\mathrm{G}$ mutation.

Prior to uracil administration, blood samples were taken to measure creatinine, alanine transaminase (ALAT), and gamma-glutamyl transpeptidase (gamma-GT) as markers for renal and liver function.

The study was approved by the local Medical Ethics Committee of Diaconessen Hospital Meppel, the Netherlands. Informed consent was obtained from each subject.

\section{Uracil administration}

Uracil (Pharmorgana GmbH, Raubling/Rosenheim, Germany) was administered orally at a test dose of $500 \mathrm{mg} / \mathrm{m}^{2}$ body surface area, calculated by the DuBois and DuBois formula, after an overnight fast (last food intake $>8 \mathrm{~h}$ earlier). All subjects had to abstain food during $2 \mathrm{~h}$ after ingesting the uracil. All the test doses were administered between 08:00 a.m. and 09:00 a.m. to avoid circadian effects. The uracil powder was mixed with 100-200 $\mathrm{mL}$ tap water, and immediately after preparation, the suspension was ingested within a few minutes. In addition, repeated administration on subsequent days ( $n=2$ in 3 subjects and $n=1$ in one subject) with $500 \mathrm{mg} / \mathrm{m}^{2}$ was performed in 4 volunteers to assess 
intra-individual variation, and $1,000 \mathrm{mg}$ uracil $/ \mathrm{m}^{2}$ was administered to 4 volunteers to assess linearity of pharmacokinetics, respectively.

\section{Collection of blood samples}

A cannula was placed intravenously in one arm of each subject. Blood samples of $5 \mathrm{ml}$ were collected in heparincontaining tubes. In an intensive sampling schedule, blood samples were collected just before and at $t=15,30,45$, $60,80,100,120,150,180$, and $220 \mathrm{~min}\left(500 \mathrm{mg} / \mathrm{m}^{2}\right)$ or $240 \mathrm{~min}\left(1,000 \mathrm{mg} / \mathrm{m}^{2}\right)$ after uracil intake. Samples were immediately placed on ice and subsequently centrifuged at $2,500 \times \mathrm{g}$ for $10 \mathrm{~min}$ at $4^{\circ} \mathrm{C}$ and stored at $-20^{\circ} \mathrm{C}$ until analysis.

For the repeated uracil administration in the 4 subjects, blood samples were collected according to a limited sampling schedule. This schedule is based on results from an interim analysis on intensive schedule results from both volunteers and patients, in which $T=60 \mathrm{~min}$ and $T=120$ min were selected as optimal sampling points for the limited sampling strategy.

\section{DPD activity}

The activity of DPD was determined in PBMCs using radiolabeled thymine followed by the separation of radiolabeled thymine from radiolabeled dihydrothymine using reversed-phase HPLC, as described before [28].

Analytical method for uracil and dihydrouracil

Uracil and DHU plasma concentrations were measured by a validated HPLC method described by Maring et al. [29]. Calibration samples were prepared by spiking human heparinized plasma (Red Cross Blood Bank, Groningen, the Netherlands) with appropriate amounts of uracil and 5,6-DHU (Sigma Chemical Co, Zwijndrecht, the Netherlands). Uracil was quantified at $266 \mathrm{~nm}$ and DHU at $205 \mathrm{~nm}$. The internal standard chlorouracil was quantified at both wavelengths. The limit of quantification in plasma was $0,004 \mathrm{mg} / \mathrm{L}$ for both uracil and $\mathrm{DHU}$.

\section{Pharmacokinetic and statistical analysis}

The pharmacokinetic parameters $T_{\max }, C_{\max }$, and AUC $_{0-180 \text { min }}$ were calculated with Phoenix ${ }^{\mathrm{TM}}$ Winnonlin $^{\circledR}$ Version 6 (Pharsight ${ }^{\circledR}$ Products, CA) using noncompartmental analysis. Mean plasma clearance was calculated with the formula Dose/AUC. Statistical analysis was performed by using SPSS version 16.0 (SPSS inc, Chicago, IL). Normality of data was tested by performing a Kolmogorov-Smirnov test.
To examine whether the uracil and DHU plasma concentrations and derived pharmacokinetic parameters differed between subjects with a normal DPD status and those with DPD deficiency, an unpaired Student's $t$ test was performed on data obtained from the $500 \mathrm{mg} / \mathrm{m}^{2}$ dose. To investigate whether the distribution of gender in both groups differs between the DPD-deficient and normal individuals, chi-square statistic was used. One-way ANOVA analysis was performed on the uracil and DHU values measured in plasma at $t=60$ and $120 \mathrm{~min}$ in the four volunteers after repeated $500 \mathrm{mg} / \mathrm{m}^{2}$ doses to study the inter- and intrasubject variability.

\section{Results}

The characteristics of the subjects included in this study are displayed in Table 1. No differences between the two groups were observed $(P>0.05)$ except for age, DPD activity, and disease status. The HPLC method that was used in this study revealed fully separated peaks for uracil and DHU in the chromatogram as is depicted in Fig. 1. The mean uracil and DHU plasma concentrations in the 11 subjects with normal DPD and in the 10 DPD-deficient subjects following an uracil dose of $500 \mathrm{mg} / \mathrm{m}^{2}$ are depicted in Fig. 2, and the estimated pharmacokinetic parameters $T_{\max }, C_{\max }, \mathrm{AUC}_{0-180 \text { min }}$, and the mean $\mathrm{Cl}$ are displayed in Table 2. $T_{\max }$ of uracil, $\mathrm{AUC}_{0-180 \mathrm{~min}}$, and $\mathrm{Cl}$ of DHU did not differ between the two groups $(P>0.05)$. All the other displayed parameters differed significantly $(P<0.05)$. After reaching $T_{\max }$, the decline of uracil concentration in both groups followed zero-order kinetics, which suggests that the DPD enzyme is fully saturated at the administered dose in both groups. In the subjects with normal DPD, after $t=100 \mathrm{~min}$, the elimination changed gradually from zero order to first order, which resulted in an exponential decline. The same phenomenon occurred in DPD-deficient subjects, although at a later stage (after $t=150 \mathrm{~min}$ ).

In subjects with normal DPD activity, uracil was completely eliminated within approximately $180 \mathrm{~min}$, whereas in DPD-deficient subjects, the uracil plasma concentration was still $2.5 \pm 2.1 \mathrm{mg} / \mathrm{L}$ indicating that in DPD-deficient individuals, the clearance of uracil was decreased. In addition, due to the reduced DPD activity, the reaction rate of the formation and the absolute amount of DHU were reduced in the group of DPD-deficient subjects. The uracil and DHU plasma concentrations measured in DPD-deficient subjects differed significantly $(P<0.05)$ as compared to the individuals with normal DPD except for uracil at $t=15 \min (P=0.071)$ and for DHU levels at $t=15$, 120,150 , and $180 \min (P=0.149, P=0.111, P=0.087$, and $P=0.363$, respectively). 
Table 1 Patient and volunteer characteristics

Values are displayed as mean $\pm \mathrm{SD}$

\begin{tabular}{llll}
\hline & $\begin{array}{l}\text { Normal DPD } \\
\text { activity }(n=11)\end{array}$ & $\begin{array}{l}\text { DPD deficient } \\
(n=10)\end{array}$ & $P$ value \\
\hline Age (years) & $38 \pm 9$ & $62 \pm 12$ & $<0.001$ \\
Sex (male/female) & $5 / 6$ & $4 / 6$ & Chi square $=0.002$ \\
Weight $(\mathrm{kg})$ & $74 \pm 10$ & $76 \pm 15$ & 0.636 \\
Height $(\mathrm{cm})$ & $177 \pm 9$ & $173 \pm 5$ & 0.154 \\
PBMC DPD $(\mathrm{nmol} / \mathrm{mg} / \mathrm{L})$ & $7.2 \pm 1.3$ & $3.6 \pm 0.8$ & $<0.001$ \\
Serum creatinine $(\mu \mathrm{mol} / \mathrm{L})$ & $80 \pm 10$ & $78 \pm 18$ & 0.707 \\
Serum ALT $(\mathrm{U} / \mathrm{L})$ & $20 \pm 8$ & $25 \pm 5$ & 0.104 \\
Serum gamma GT $(\mathrm{U} / \mathrm{L})$ & $16 \pm 6$ & $39 \pm 40$ & 0.160 \\
\hline
\end{tabular}

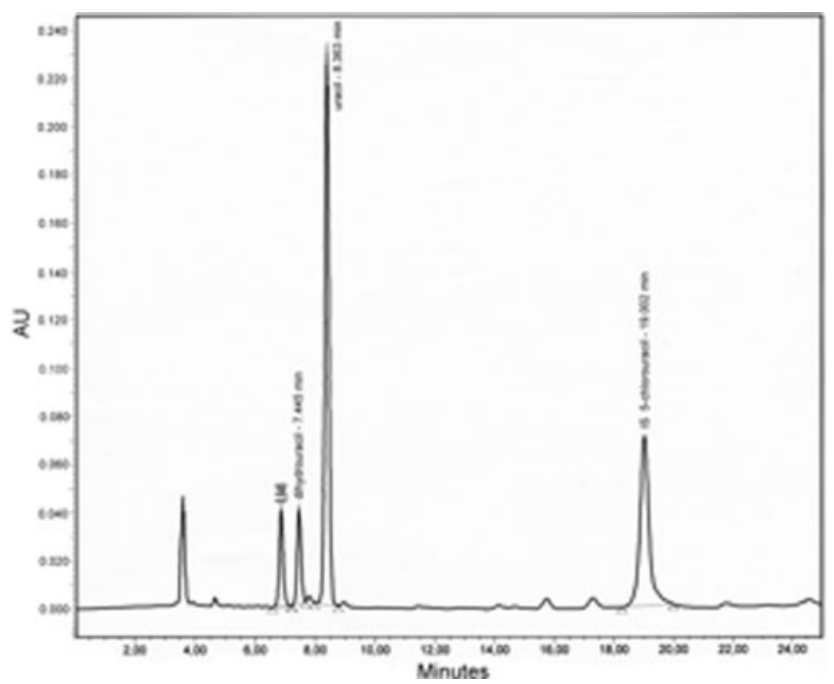

Fig. 1 Representative chromatogram obtained from a blood sample of a DPD-deficient patient at $t=101 \mathrm{~min}$ after oral intake of $500 \mathrm{mg} /$ $\mathrm{m}^{2}$ uracil. The chromatogram was recorded at $205 \mathrm{~nm}$. The uracil and dihydrouracil concentrations were estimated as 7.60 and $2.03 \mathrm{mg} / \mathrm{L}$, respectively

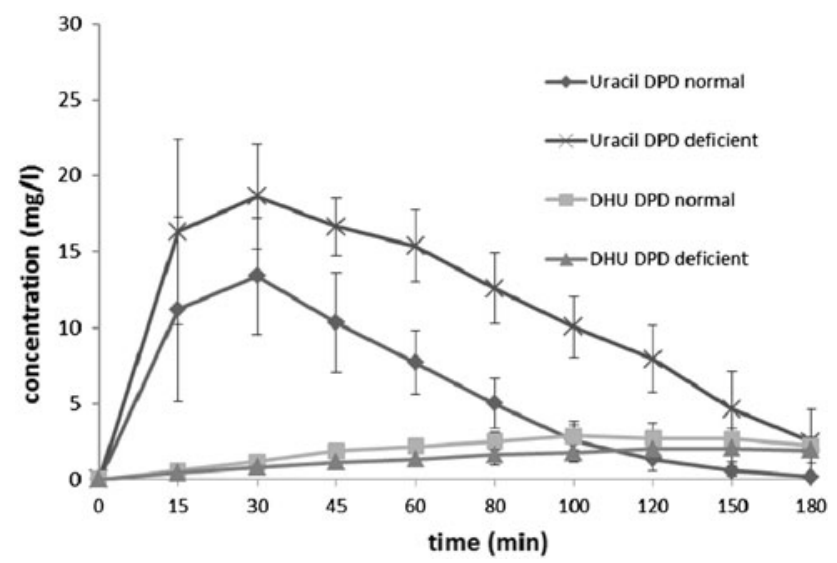

Fig. 2 Concentration-time profile of uracil and DHU in subjects with normal DPD $(n=11)$ and DPD-deficient subjects $(n=10)$ after oral intake of $500 \mathrm{mg} / \mathrm{m}^{2}$ uracil suspension. The results shown are the mean $\pm \mathrm{SD}$
Comparable uracil concentrations at $t=60$ and $120 \mathrm{~min}$ were observed in subjects with normal DPD status who were tested multiple times. However, significant differences were observed for DHU levels at $t=60$ and $120 \min (P=0.012$ resp. $P=0.001$ ).

Figure 3 shows the plasma concentrations of uracil and DHU after administration of $1,000 \mathrm{mg}$ uracil $/ \mathrm{m}^{2}$ compared with $500 \mathrm{mg}$ uracil $/ \mathrm{m}^{2}$ in subjects with normal DPD status. The $C_{\max }$ of both curves is reached after approximately $30 \mathrm{~min}\left(T_{\max }\right)$. Only after $45 \mathrm{~min}$, the uracil levels differed significantly between both dosages. For DHU, the concentrations after ingestion of both doses differed not significantly the first $100 \mathrm{~min}$, but after this point, the DHU concentrations measured in the group of $1,000 \mathrm{mg} / \mathrm{m}^{2}$ were significantly higher. The $C_{\max }$ values of uracil and DHU (Table 2) at $1,000 \mathrm{mg} / \mathrm{m}^{2}$ are, respectively, $1.7 \pm 0.3$ and $1.5 \pm 0.4$ times higher compared with those after $500 \mathrm{mg} / \mathrm{m}^{2}$.

\section{Discussion}

In this study, it is shown that the pharmacokinetics of uracil after an oral uracil dose of $500 \mathrm{mg} / \mathrm{m}^{2}$ was significantly different in subjects with DPD deficiency as compared to those with a normal DPD status suggesting that oral uracil administration may be useful as a test to determine patients with DPD deficiency.

The patient characteristics of the two groups in which we studied uracil and DHU pharmacokinetics were comparable except for DPD status, age, and disease state. The subjects with normal DPD consisted of young healthy individuals, in contrast to the subjects with DPD deficiency, who were all colorectal and breast cancer patients. Aging involves progressive impairments in the functional reserve of multiple organs, which might also affect drug metabolism and pharmacokinetics [30]. With age, the liver mass and its perfusion decreases causing a diminished first pass effect of highly cleared drugs, and renal clearance of 
Table 2 Pharmacokinetic parameters of $500 \mathrm{mg} / \mathrm{m}^{2}$ and $1,000 \mathrm{mg} / \mathrm{m}^{2}$ in volunteers and $500 \mathrm{mg} / \mathrm{m}^{2}$ in patients

\begin{tabular}{|c|c|c|c|c|c|c|c|c|}
\hline & \multicolumn{2}{|c|}{ Normal DPD activity } & \multicolumn{2}{|l|}{ DPD deficient } & \multicolumn{2}{|c|}{$\begin{array}{l}P \text { value } \\
\left(500 \mathrm{mg} / \mathrm{m}^{2}\right)\end{array}$} & \multicolumn{2}{|c|}{ Normal DPD activity } \\
\hline & $\begin{array}{l}\text { Uracil } 500 \\
\mathrm{mg} / \mathrm{m}^{2}(n=11)\end{array}$ & $\begin{array}{l}\text { DHU } 500 \\
\mathrm{mg} / \mathrm{m}^{2}(n=11)\end{array}$ & $\begin{array}{l}\text { Uracil } 500 \\
\mathrm{mg} / \mathrm{m}^{2}(n=10)\end{array}$ & $\begin{array}{l}\text { DHU } 500 \\
\mathrm{mg} / \mathrm{m}^{2}(n=10)\end{array}$ & Uracil & DHU & $\begin{array}{l}\text { Uracil } 1,000 \\
\mathrm{mg} / \mathrm{m}^{2}(n=4)\end{array}$ & $\begin{array}{l}\text { DHU } 1,000 \\
\mathrm{mg} / \mathrm{m}^{2}(n=4)\end{array}$ \\
\hline$T_{\max }(\min )$ & $30.0 \pm 11.6$ & $104.5 \pm 23.4$ & $31.5 \pm 11.1$ & $166.0 \pm 55.6$ & 0.765 & 0.007 & $33.8 \pm 18.9$ & $195.0 \pm 57.4$ \\
\hline$C_{\max }(\mathrm{mg} / \mathrm{L})$ & $14.4 \pm 4.7$ & $3.0 \pm 0.9$ & $20.0 \pm 4.5$ & $2.2 \pm 0.9$ & 0.011 & 0.046 & $24.1 \pm 11.9$ & $5.2 \pm 1.1$ \\
\hline $\begin{array}{l}\mathrm{AUC}_{0-180 \mathrm{~min}} \\
(\mathrm{mg} \mathrm{h} / \mathrm{L})\end{array}$ & $13.8 \pm 3.9$ & $5.9 \pm 1.9$ & $31.2 \pm 5.1$ & $4.4 \pm 1.7$ & $<0.001$ & 0.074 & $36.0 \pm 14.4$ & $8.0 \pm 2.3$ \\
\hline $\mathrm{Cl}_{\text {mean }}(\mathrm{L} / \mathrm{min})$ & $1.3 \pm 0.5$ & $3.1 \pm 1.8$ & $0.5 \pm 0.1$ & $4.0 \pm 1.6$ & $<0.001$ & 0.230 & $1.1 \pm 0.6$ & $4.5 \pm 1.7$ \\
\hline
\end{tabular}

Values are displayed as mean $\pm \mathrm{SD}$

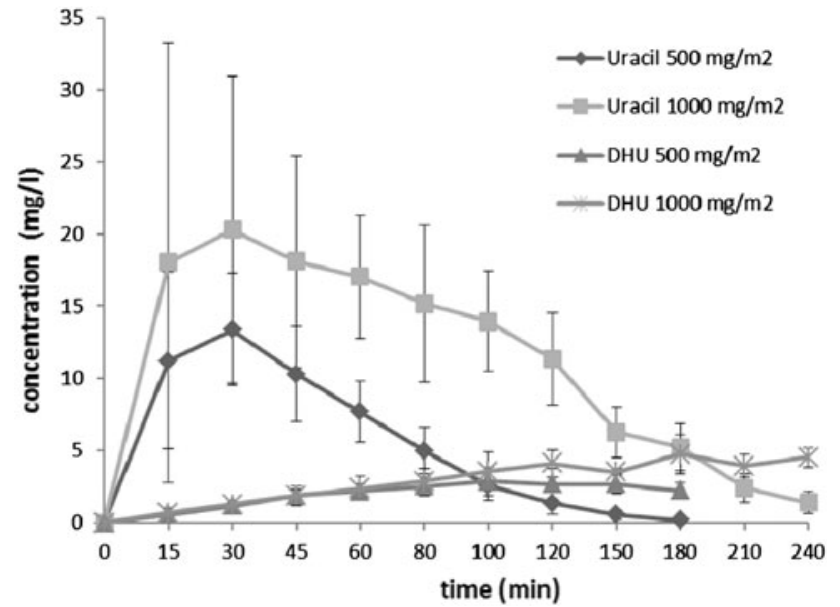

Fig. 3 Concentration-time profile of uracil and DHU in subjects with normal DPD activity after oral administration of a dose of $500 \mathrm{mg} / \mathrm{m}^{2}$ $(n=11)$ and $1,000 \mathrm{mg} / \mathrm{m}^{2}(n=4)$ uracil suspension. The results shown are the mean \pm SD

drugs is reduced by the loss of kidney function [31]. The liver contains a high amount of DPD, so increasing age might lead to reduced first pass effect and metabolism of uracil in the liver causing higher plasma concentrations in elderly compared with younger individuals. In addition, in cancer patients, metastases of the liver and steatosis caused by systemic chemotherapy [32] can reduce liver drug metabolism, which may also lead to changes in uracil metabolism. However, Maring et al. [33] described that extensive hepatic replacement due to liver metastases had no effect on 5-fluorouracil pharmacokinetics, indicating that the amount of DPD is probably not influenced by reduction in liver function. In addition, in our study population of DPD-deficient patients receiving systemic chemotherapy, no significant differences were observed in liver function or serum creatine compared with the group of healthy individuals. As a result of these findings, we consider it unlikely that the 2.6 -fold decrease in clearance of uracil can be ascribed to differences in age or disease state between the two groups. The differences between the
2 uracil curves representing both the groups with and without DPD deficiency at $500 \mathrm{mg} / \mathrm{m}^{2}$ are caused by the amount of DPD available in deficient subjects, which is lower than in subjects with normal DPD activity causing reduced clearance of uracil. Mattison et al. [15] evaluated fixed doses of $2-{ }^{13} \mathrm{C}$-uracil of 100,200 , and $300 \mathrm{mg}$ as well as doses adjusted to body weight $(1,3,6$, and $12 \mathrm{mg} / \mathrm{kg})$. They demonstrated with their uracil breath test that an administered dose of $6 \mathrm{mg} / \mathrm{kg} 2{ }^{13} \mathrm{C}$-uracil generated less variable $C_{\max }$ and $T_{\max }$ than single fixed doses of 100, 200, or $300 \mathrm{mg}$. The dose of $500 \mathrm{mg}$ uracil $/ \mathrm{m}^{2}$ used in our study is in range with the $2{ }^{13} \mathrm{C}$-uracil dose of $12 \mathrm{mg} / \mathrm{kg}$ that was also used by Mattison et al. and with the commonly applied 5 -FU bolus doses of $400-600 \mathrm{mg} / \mathrm{m}^{2}$ in the treatment of colorectal and breast cancer [34-37]. The gastrointestinal absorption of uracil is a pharmacokinetic first-order process, and the elimination follows a reversible and saturable Michaelis-Menten kinetics [17]. When DPD is saturated, the elimination of uracil follows zero-order kinetics. The formation of DHU depends on the Km of DPD and the amount of uracil and enzyme present. When all the present DPD enzyme is saturated, the metabolism of uracil will depend on the absolute amount of DPD present and not on the amount of uracil, i.e., if the same dose of uracil is administered to two individuals with different enzyme levels, the individual with the highest amount of enzyme will have the highest "zero-order" reaction rate and the lowest $C_{\max }$ of both individuals. So, in order to discriminate between individuals with a normal DPD activity and those with a DPD deficiency, the uracil dose used needs to be high enough to saturate the DPD enzyme both in individuals with and without DPD deficiency in order to achieve significant different plasma levels.

For oral uracil to be used as a diagnostic test, the pharmacokinetics of uracil between patients with and without DPD deficiency has to be clearly discriminating. Mattison et al. [38] describe that the AUC following a dose of $6 \mathrm{mg} / \mathrm{kg} 2-{ }^{13} \mathrm{C}$ uracil is significantly different in subjects with normal DPD activity versus partial DPD deficiency. 
This is in line with the results we found using a dose $500 \mathrm{mg} / \mathrm{m}^{2}$ uracil. For a broad clinical use, a diagnostic test has to be simple, cheap, sensitive, and specific. The uracil breath test is expensive because of the use of $2-{ }^{13} \mathrm{C}$ uracil and breath bags, and the technique of IR spectrophotometry for analysis of exhaled samples is not available in every hospital. Our test might be more cost effective and might lead to quick test results since the price of 1 gram uracil is about 1 US\$ and the HPLC equipment that is used for analysis is common in most hospitals for therapeutic drug monitoring purposes. If the HPLC equipment is not available at the testing site, the plasma samples have to be stable enough to be transported. Prior to this study, the stability of $\mathrm{U}$ and DHU in whole blood and plasma was determined. The results show that uracil in whole blood can be stored at $4{ }^{\circ} \mathrm{C}$ for up to $4 \mathrm{~h}$. The degradation of $\mathrm{U}$ and DHU in plasma was less than $2 \%$ during $24 \mathrm{~h}$ at room temperature. We therefore concluded that the stability in plasma is sufficient enough to perform the analytical extraction procedure without further precautions and that the plasma samples are suitable for transportation within $24 \mathrm{~h}$. As a result, our test can be incorporated broadly into common clinical practice. However, a disadvantage of the current setup of the test is the intensive blood sampling scheme that takes $4 \mathrm{~h}$ to perform and makes the patient intense. The test has to be further optimized into a limited sampling strategy to be more patient friendly. Based on a limited sampling strategy, the parameters AUC, clearance, and $C_{\max }$ are less suitable for discriminating, but the uracil and/ or DHU concentrations or U/DHU ratio at selected time points (e.g. 120 min after administration) might be. At this stage, it is unclear if monitoring DHU concentrations can be useful in a limited sampling strategy setting since we found only slightly different values in DHU pharmacokinetic parameters in both groups. This might be explained by the fact that the DHU levels are not only determined by the degradation of uracil by DPD but also by its volume of distribution and the subsequent hydrolysis of DHU into $\mathrm{N}$-carbamyl- $\beta$-alanine by dihydropyrimidinase. We conclude that uracil administration at a single dose of $500 \mathrm{mg} / \mathrm{m}^{2}$ leads to significant and reproducible differences in pharmacokinetics of uracil and DHU between volunteers with a normal DPD activity and DPD-deficient patients. $\mathrm{AUC}_{0-180 \text { min }}$ and $C_{\max }$ might be useful to detect partial DPD deficiency. In addition, uracil doses above $500 \mathrm{mg} / \mathrm{m}^{2}$ have no discriminating benefits but will only result in a right shift of the uracil and DHU concentration curve and unnecessary longer exposition to high uracil levels. The results presented here points toward a promising development of an oral uracil challenge as a diagnostic test for DPD deficiency. The sensitivity and specificity of this test are currently investigated in a larger population of cancer patients with and without DPD deficiency.
Open Access This article is distributed under the terms of the Creative Commons Attribution Noncommercial License which permits any noncommercial use, distribution, and reproduction in any medium, provided the original author(s) and source are credited.

\section{References}

1. Pinedo HM, Peters GF (1988) Fluorouracil: biochemistry and pharmacology. J Clin Oncol 6(10):1653-1664

2. Diassio RB, Harris BE (1989) Clinical pharmacology of 5-fluorouracil. Clin Phamacokinet 16:215-237

3. Etienne MC, Lagrange JL, Dassonville O et al (1994) Population study of dihydropyrimidine dehydrogenase in cancer patients with advanced colorectal cancer. J Clin Oncol 12(11):2248-2253

4. Flemming RA, Milano G et al (1992) Correlation between dihydropyrimidine dehydrogenase activity in peripheral mononuclear cells and systemic clearance of fluorouracil in cancer patients. Cancer Res 52:2899-2902

5. Harris BE, Song R (1990) Relation between dihydropyrimidine dehydrogenase and plasma 5-fluorouracil levels with evidence for circadian variation of enzyme activity and plasma drug levels in cancer patients receiving 5-fluorouracil bij protracted continuous infusion. Cancer Res 50:197-201

6. Maring JG, van Kuilenburg ABP, Haasjes J et al (2002) Reduced 5-FU clearance in a patient with low DPD activity due to heterozygosity for a mutant allele of the DPYD gene. Br J Cancer 86:1028-1033

7. van Kuilenburg ABP, Maring JG, Schalhom A et al (2008) Pharmacokinetics of 5-fluorouracil in patients heterozygous for the IVS14 + 1G $>$ A mutation in the dihydropyrimidine dehydrogenase gene. Nucleosides Nucleotides Nucleic Acids 27:692-698

8. Ciccolini J, Mercier C, DAhan L, Evrard A, Boyer JC, Richard K, Dales JP, Durand A, Milano G, Seitz JF, Lacarelle B (2006) Toxic death-case after capecitabine + oxaliplatin (XELOX) administration: probable implication of dihydropyrimidine dehydrogenase deficiency. Cancer Chemother Pharmacol 58:272275

9. Mercier C, Ciccolini J (2007) Severe or lethal toxicities upon capecitabine intake: is DPYD genetic polymorphism the ideal culprit? Trends Pharmacol Sci 28(12):597-598

10. van Kuilenburg ABP, Haasjes J, Richel D et al (2006) Clinical implications of dihydropyrimidine dehydrogenase (DPD) deficiency in patients with severe 5-Fluorouracil-associated toxicity: identification of new mutations in the DPD gene. Clin Cancer Res 6:4705-4712

11. van Kuilenburg ABP, Meinsma R, Zoetekouw L, van Gennip AH (2002) Increased risk of grade IV neutropenia after administration of 5-FU due to a dihydropyrimidine dehydrogenase deficiency: high prevalence of the IVS14 $+1 \mathrm{G}>\mathrm{A}$ mutation. Int $\mathrm{J}$ Canc 101:253-258

12. Boisdron-Celle M, Remaud G, Traore S, Poirier AL, Gamelin L, Morel A, Gamelin E (2007) 5-Fluorouracil-related toxicity: a comparison of different methods for the pretherapeutic detection of dihydropyrimidine dehydrogenase deficiency. Cancer Lett 249:271-282

13. Yang CG, Ciccolini J, Blesius A, Dahan L, Bagarry-Liegey D, Brunet $C$ et al (2010) DPD-based adaptive dosing of 5-FU in patients with head and neck cancer: impact on treatment efficacy and toxicity. Cancer Chemother Pharmacol 67:49-56

14. van Kuilenburg ABP, Meinsma R, Zoetekouw L et al (2002) High prevalence of the IVS14 $+1 \mathrm{G}>\mathrm{A}$ mutation in the dihydropyrimidine dehydrogenase gene of patients with severe 5-fluorouracil-associated toxicity. Pharmacogenetics 12(7):555558 
15. Mattison LK, Fourie J, Hirao Y, Koga T, Desmond RA, King JR, Shimizu T, Diasio RB (2006) The uracil breath test in the assessment of dihydropyrimidine dehydrogenase activity: pharmacokinetic relationship between expired ${ }^{13} \mathrm{CO}_{2}$ and plasma $\left[2-{ }^{13} \mathrm{C}\right]$ dihydrouracil. Clin Cancer Res 12:549-555

16. Mattison LK, Ezzeldin H, Carpenter M, Modak A, Johnson MR, Diasio RB (2004) Rapid identification of dihydropyrimidine dehydrogenase deficiency by using a novel $2-{ }^{13} \mathrm{C}$-uracil breath test. Clin Cancer Res 10:2652-2658

17. Ito S, Kawamura $T$, Inada $M$ et al (2005) Physiologically modelling of the three-step metabolism of pyrimidine using ${ }^{13} \mathrm{C}$-uracil as an in vivo probe. British J of Clinical Pharmacol 60(6):584593

18. Escoriaza J, Aldaz A, Calvo E et al (1999) Simple and sensitive determination of 5-fluorouracil in plasma by high-performance liquid chromatography. Application to clinical pharmacokineticstudies. J Chromatogr B Biomed Sci Appl 736(12):97-102

19. Kristensen MH, Pedersen P, Mejer J (2010) The value of dihydrouracil/uracil plasma ratios in predicting 5-Fluorouracil-related toxicity in colorectal cancer patients. J Int Med Res 38(4):13131323

20. Bocci G, Barbara C, Vannozzi F, Di Paolo A, Melosi A, Barsanti G, Allegrini G, Falcone A, Del Tacca M, Danesi R (2006) A pharmacokinetic-based test to prevent severe 5-fluorouracil toxicity. Clin Pharmacol Ther 80(4):384-395

21. Bocci G, Di Paolo A, Barbara C, Masi G, Fornaro L et al (2010) Pharmacokinetics, a main actor in a many-sided approach to severe 5-FU toxicity prediction. Br J of Clin Pharmacol 67(1): $132-134$

22. Ciccoline J, Mercier C, Evrard A, Boyer JC, Duffaud F, Dhan L, Richard K, Blanquicett C, Blesius A, Durand A, Seitz JF, Favre $\mathrm{R}$, Lacarelle B (2006) A rapid and inexpensive method for anticipating severe toxicity to fluorouracil and fluorouracil-based chemotherapy. Ther Drug Monit 28(5):678-685

23. Daoqin B, Anderson LW, Shapiro J, Shapiro A, Grem JL, Takimoto CH (2000) Measurement of plasma uracil using gas chromatography-mass spectrometry in normal individuals and in patients receiving inhibitors of dihydropyrimidine dehydrogenase. J Chromatorgr B 738:249-258

24. Fredj RB, Gross E, Ahmed SB, Hassine H, Saguem S (2009) The dihydrouracil/uracil ratio in plasma, clinical and genetic analysis or screening of dihydropyrimidine dehydrogenase deficiency in colorectal cancer patients treated with 5-fluorouracil. Pathol Biol 57(6):470-476

25. Ciccolini J, Mecier C, Blanchon MF, Favre R, Durand A, Lacarelle B (2004) A simple and rapid high-performance liquid chromatographic (HPLC) assay in plasma and possible detection of patients with impaired dihydropyrimidine dehydrogenase (DPD) activity. J Clin Pharm Ther 29:307-315

26. Zhou ZW, Wang GQ, de Wan S, Lu ZH, Chen YB, Li S, Chen G, Pan ZZ (2007) The dihydrouracil/uracil ratios in plasma and toxicities of 5-fluorouracil-based adjuvant chemotherapy in colorectal cancer patients. Chemotherapy 53(2):127-131
27. Gamelin E, Boisdron-Celle M, Guérin-Meyer V, Delva R, Lortholary A, Genevieve F, Larra F, Ifrah N, Robert J (1999) Correlation between uracil and dihydrouracil plasma ratio, fluorouracil (5-FU) pharmacokinetic parameters, and tolerance in patients with advanced colorectal cancer: A potential interest for predicting 5-FU toxicity and determining optimal 5-FU dosage. J Clin Oncol 17(4):1105-1110

28. van Kuilenburg ABP, van Lenthe $H$, Tromp A, Veltman PCJ, van Gennip AH (2000) Pitfalls in the diagnosis of patients with a partial dihydropyrimidine dehydrogenase deficiency. Clin Chem 46:9-17

29. Maring JG, Schouten L, Greijdanus B, de Vries EG, Uges DR (2005) A simple and sensitive fully validated HPLC-UV method for the determination of 5-fluorouracil and its metabolite 5, 6-dihydrofluorouracil in plasma. Ther Drug Monit 27(1):25-30

30. Klotz U (2009) Pharmacokinetics and drug metabolism in the elderly. Drug Metab Rev 41(2):67-76

31. Aymanns C, Keller F, Maus S, Hartmann B et al (2010) Review on pharmacokinetics and pharmacodynamics and the aging kidney. Clin J Am Soc Nephrol 5(2):314-327

32. Ramadori G, Cameron S (2010) Effects of systemic chemotherapy on the liver. Ann Hepatol 9(2):133-143

33. Maring JG, Piersma H, van Dalen A, Groen HJ, Uges DR, De Vries EG (2003) Extensive hepatic replacement due to liver metastases has no effect on 5-fluorouracil pharmacokinetics. Cancer Chemother Pharmacol 51(2):167-173

34. O'Connell MJ (1989) A phase III trial of 5-fluorouracil and leucovorin in the treatment of advanced colorectal cancer. A Mayo Clinic/North Central Cancer Treatment Group study. Cancer 63:1026-1030

35. Rothenberg ML, Oza AM, Bigelow RH, Berlin JD, Marshall JL, Ramanathan RK et al (2003) Superiority of oxaliplatin and fluorouracil and fluorouracil-leucovorin compared with either therapy alone in patients with progressive colorectal cancer after irinoctecan and fluorouracil-leucovorin: interi results of a phase III trial. J Clin Oncol 21:1897-1905

36. Stewart DJ, Evans WK, Shepard FA, Wilson KS, Pritchard KI, Trudeau MF et al (1997) Cyclofosfamide and fluorouracil combined with mitoxantrone versus doxorubicin for breast cancer: superiority of doxorubicin. J Clin Oncol 15:1897-1905

37. Amadori D, Nanni O, Marangolo M, Pacini R, Ravaioli A, Rossi A et al (2000) Disease-free survival advantage of adjuvant cyclophosphamide, methotrexate, and fluorouracil in patients with node-negative, rapidly proliferating breast cancer: a randomised multicenter study. J Clin Oncol 18:3125-3134

38. Mattison K, Fourie J, Hirao Y, Koga T et al (2006) The uracil breath test in the assessment of dihydropyrimidine dehydrogenase activity: pharmacokinetic relationship between expired ${ }^{13} \mathrm{CO}_{2}$ and plasma $\left[2-{ }^{13} \mathrm{C}\right]$ dihydrouracil. Clin Cancer Res 12(2): 549-555 